\title{
Implementasi Model SCORPIO Sebagai Strategi Pemasaran Pelaku Usaha Mikro \& Kecil Pada Masa Pandemi Covid-19
}

\author{
Erwin Yulianto*1, Vera Fauziah ${ }^{2}$, Wita Wahyuni Subangkit ${ }^{3}$, Wulan Fauziah ${ }^{4}$ \\ ${ }^{1}$ Universitas Langlangbuana, Indonesia \\ ${ }^{2,3,4}$ Universitas Garut, Indonesia \\ ${ }^{1}$ Jl. Karapitan No. 116, Kota Bandung, Jawa Barat, Indonesia \\ ${ }^{2,3,4}$ Kampus 4 Universitas Garut, Jalan Terusan Pahlawan Kec. Tarogong Kab. Garut, Indonesia \\ *rwinyulianto@yahoo.com
}

\begin{abstract}
Abstrak- The current COVID-19 pandemic has had a major economic impact on the Micro, Small, and Medium Enterprises (UMKM) sector. This is because, in terms of the economy in general, Micro, Small, and Medium Enterprises (UMKM) occupy a very strategic position. One way to get a sustainable competitive advantage in a service or goods production business is to have a good marketing strategy. This study aims to examine how the implementation of the SCORPIO Model in the Marketing Strategy of Small Business Actors during the COVID-19 Pandemic. This study also aims to convey or describe marketing strategies for Small Business Actors by utilizing the SCORPIO Model. This study uses a descriptive qualitative method that will use some literature such as books, articles, or homepages as secondary data sources. The COVID-19 pandemic has had a major impact on the MSME economy in Indonesia. With the implementation of this Scorpio model on the marketing strategy of small business actors or UMKM, it can help maintain business during this pandemic with 7 components in the SCORPIO model.
\end{abstract}

Keywords : SCORPIO Model; Marketing Strategy; Covid-19 Pandemic.

\begin{abstract}
Abstrak
Pandemi COVID-19 yang terjadi saat ini memberikan dampak ekonomi yang besar kepada sektor Usaha Mikro, Kecil, dan Menengah (UMKM). Hal tersebut dikarenakan dalam hal perekonomian secara umum, Usaha Mikro, Kecil, dan Menengah (UMKM) menempati posisi yang sangat strategis. Salah satu cara untuk mendapatkan keunggulan persaingan yang berkelanjutan dalam sebuah usaha produksi jasa atau barang ialah dengan memiliki strategi pemasaran yang baik. Penelitian ini bertujuan untuk menguji bagaimana Implementasi Model SCORPIO Pada Strategi Pemasaran Pelaku Usaha Kecil Pada Masa Pandemi Covid-19. Penelitian ini juga bertujuan untuk menyampaikan atau menggambarkan strategi pemasaran bagi Pelaku Usaha Kecil dengan memanfaatkan Model SCORPIO. Penelitian ini menggunakan metode kualitatif deskriptif yang akan menggunakan beberapa literature seperti buku, artikel, ataupun homepage sebagai sumber data sekunder. Pandemi COVID-19 memberikan dampak yang besar pada perekonomian UMKM di Indonesia. Dengan implementasi model scorpio ini terhadapa strategi pemasaran pelaku usaha kecil atau UMKM bisa membantu mempertahankan usaha di masa pandemic ini dengan 7 komponen yang ada di model Scorpio.
\end{abstract}

Kata Kunci - Model SCORPIO; Strategi Pemasaran; Pandemi Covid-19.

\section{PENDAHULUAN}

Pandemi yang saat ini sedang terjadi disebabkan oleh Coronavirus Disease 2019 atau yang biasa disebut dengan COVID-19 menjadi masalah kesehatan bagi dunia saat ini begitu pula dengan Indonesia. Tercatat hingga 30 Mei 2020, COVID-19 telah menyebar hampir di seluruh negara dengan total menyentuh angka 6 juta yang telah terinfeksi dengan angka kematian tiap 1 juta penderita yaitu menyentuh angka 47 orang[1]. Indonesia sendiri saat ini berada pada posisi 32 dunia untuk total kasus infeksi COVID-19 [2].

Pandemi yang terjadi akibat COVID-19 ini juga memberikan dampak ekonomi yang sangat besar terutama pada sektor Usaha Mikro, Kecil, dan Menengah (UMKM)[2]. Hal tersebut dikarenakan UMKM memiliki tempat yang strategis dalam hal perekonomian secara umum. Tercatat di area ASEAN, UMKM dapat memberikan kontribusi lapangan pekerjaan dari $50 \%$ hingga $95 \%$ pada masyarakat, selain itu juga memiliki kontribusi pada GDP antara $30 \%$ hingga $50 \%$. UMKM tumbuh dan berkembang dengan bagus di Indonesia, UMKM dapat memberikan banyak lapangan pekerjaan, selain itu juga UMKM di Indonesia cukup adaptif dan memiliki inovasi yang baik sehingga dapat bertahan sekalipun dalam kondisi yang tidak menguntungkan dan kondisi sulit seperti saat ini [3] .

Persaingan yang terjadi antar perusahaan dalam usaha memenuhi kebutuhan konsumen dengan memberikan jasa dan produk yang terbaik pun pada akhirnya menimbulkan pertumbuhan ekonomi dan juga perkembangan ilmu pengetahuan teknologi terkait dunia perekonomian. Dalam dunia 
perekonomian akan selalu terjadi perubahan dalam strategi pemasaran, hal tersebut dikarenakan kondisi pasar akan selalu mengalami perubahan dan menyebabkan perusahaan harus siap beradaptasi dengan kondisi pasar terkini dengan cara selalu memperbarui sistem pemasaran yang dapat sesuai dengan situasi pasar dan kondisi dari konsumen terkini [4].

Salah satu cara untuk mendapatkan keunggulan persaingan yang berkelanjutan dalam sebuah usaha produksi jasa atau barang ialah dengan memiliki strategi pemasaran yang baik. Dalam proses penyusunan perencanaan sebuah UMKM secara menyeluruh, strategi pemasaran merupakan salah satu pondasi yang harus dipikirkan secara matang. Dilihat dari permasalahan yang ada pada sebuah usaha, adanya perencanaan yang dapat digunakan sebagai pedoman bagi usaha tersebut dalam menjalankan kegiatannya merupakan sebuah aspek penting. Strategi pemasaran juga sangat penting untuk dipersiapkan dikarenakan semakin ketatnya persaingan yang terjadi antar perusahaan [5] .

Dalam proses menetapkan strategi pemasaran sebuah UMKM harus dilakukan secara matang agar diharapkan dapat menguasai pasar. Hal tersebut sangat krusial dikarenakan semakin ketatnya persaingan antar perusahaan sehingga tiap UMKM dituntut untuk dapat merebut pangsa pasar [6].

Kegiatan penelitian ini dilakukan dengan tujuan untuk melakukan tes uji mengenai Implementasi Model SCORPIO Pada Strategi Pemasaran Pelaku Usaha Kecil Pada Masa Pandemi COVID-19. Selain itu juga dimaksudkan untuk dapat menggambarkan bagaimana strategi pemasaran Model SCORPIO Pada Strategi Pemasaran Pelaku Usaha Kecil.

\section{KAJIAN PUSTAKA}

\section{A. USAHA MIKRO, KECIL \& MENENGAH Usaha Mikro}

Usaha Mikro merupakan sebuah usaha produktif yang dimiliki oleh perorangan yang telah sesuai dengan ketentuan kriteria Usaha Mikro. Kriteria yang dimiliki oleh Usaha Mikro antara lain [7]:

1. Mempunyai maksimal Rp50.000.000,00 (lima puluh juta rupiah) kekayaan bersih yang tidak melingkupi bangunan dan tanah dari tempat usaha.

2. Mempunyai maksimal Rp300.000.000,00 (tiga ratus juta rupiah) hasil penjualan tahunan.

\section{Usaha Kecil}

Usaha Kecil merupakan sebuah usaha produktif yang berdiri sendiri oleh perorangan atau sebuah badan usaha yang bukan bagian atau turunan perusahaan atau cabang perusahaan yang dikuasai, dimiliki, atau bagian baik secara langsung ataupun tidak dari Usaha Menengah atau Usaha Besar yang memiliki kriteria sesuai dengan ketentuan kriteria Usaha Kecil. Kriteria yang dimiliki oleh Usaha Kecil antara lain [7]:

1. Mempunyai kekayaan bersih dengan rentang Rp50.000.000,00 (lima puluh juta rupiah) hingga Rp300.000.000,00 (tiga ratus juta rupiah) yang tidak melingkupi bangunan dan tanah dari tempat usaha.

2. Mempunyai hasil penjualan tahunan dengan rentang Rp300.000.000,00 (tiga ratus juta rupiah) hingga Rp2.500.000.000,00 (dua milyar lima ratus juta rupiah).

\section{Usaha Menengah}

Usaha Menengah merupakan sebuah usaha produktif yang berdiri sendiri oleh perorangan atau sebuah badan usaha yang bukan bagian atau turunan perusahaan atau cabang perusahaan yang dikuasai, dimiliki, atau bagian baik secara langsung ataupun tidak dari Usaha Kecil atau Usaha Besar yang sesuai dengan ketentuan kriteria Usaha Menengah. Kriteria yang dimiliki oleh Usaha Menengah antara lain [7]:

1. Mempunyai kekayaan bersih dengan rentang Rp500.000.000,00 (lima ratus juta rupiah) hingga Rp10.000.000.000,00 (sepuluh milyar rupiah) yang tidak melingkupi bangunan dan tanah dari tempat usaha.

2. Mempunyai hasil penjualan tahunan dengan rentang Rp2.500.000.000,00 (dua milyar lima ratus juta rupiah) hingga Rp50.000.000.000,00 (lima puluh milyar rupiah).

\section{Karakteristik Usaha Mikro, Kecil, dan Menengah (UMKM)}

Terdapat beberapa jenis dari karakteristik yang dapat dilihat dari sebuah usaha UMKM, berdasarkan studi dari Lembaga Pengembangan Perbankan Indonesia dengan Bank Indonesia pada tahun 2015 berikut ini merupakan jenis karakteristik tersebut [8]:

1. Terbatasnya jenis dari jasa atau produk yang ditawarkan, UMKM umumnya hanya menawarkan atau memproduksi beberapa jenis jasa atau produk saja. Akan memerlukan waktu lebih apabila mendapatkan sebuah permintaan untuk model produk atau jasa yang tidak biasa.

2. Belum memiliki standar pada kualitas jasa atau produk yang dimiliki, hal tersebut dikarenakan pada umumnya UMKM belum memiliki modal teknologi ataupun kemampuan yang memadai.

\section{(i) (2)}


Umumnya UMKM masih menawarkan jasa atau produk berupa handmade.

3. Kurangnya standar dalam pemilihan bahan baku, hal tersebut dikarenakan oleh sumber bahan baku yang berbeda-beda yang mana kualitas dari bahan baku tersebut akan berpengaruh pada hasil produk.

4. Terbatasnya desain dari produk yang ditawarkan, hal tersebut disebabkan masih terbatasnya pengalaman dan juga kemampuan UMKM terhadap produk atau jasa yang mereka tawarkan. Sebagian besar UMKM bekerja mengikuti permintaan dari konsumennya sehingga banyak yang kurang berkreasi membuat desain baru.

5. Kurang terjaminnya umur atau keberlangsungan produksi dari sebuah produk, hal tersebut dikarenakan produksi yang dilakukan oleh UMKM pada umumnya masih kurang konsisten sehingga berpengaruh pada kualitas produk yang dihasilkan.

6. Terbatasnya kapasitas dan daftar dari produk yang dihasilkan. Hal tersebut disebabkan karena banyak UMKM yang masih cenderung mengalami kesulitan dalam memutuskan kapasitas produksi dan juga harga dari produk atau jasa yang ditawarkan.

\section{B. STRATEGI PEMASARAN}

Strategi merupakan sebuah rencana yang komprehensif mengintegrasikan segala resources dan capabilities yang mempunyai tujuan jangka panjang untuk memenangkan kompetisi [9]. Yang dimaksud dengan strategis yaitu sebuah kerangka kerja yang dapat memberikan panduan ataupun pilihan yang dapat membantu penetapan arah atau keputusan sebuah organisasi. 'Doing the right things', atau kerjakan sesuatu dengan benar merupakan penjabaran singkat dari strategi.

Sebuah strategi pemasaran sangat berhubungan dengan dua hal berikut, pertama ialah terkait dengan konsumen, seperti apa konsumen yang menjadi target pasar dari perusahaan. Dalam hal konsumen, perusahaan harus dapat memutuskan segmentasi pasar dan sasaran pasar yang menjadi target. Kedua ialah terkait dengan value untuk sasaran pasar. Dalam hal tersebut pihak perusahaan harus dapat memutuskan diferensiasi dan juga positioning terhadap target konsumen [10].

Perumusan strategi merupakan proses penyusunan langkah-langkah ke depan yang dimaksudkan untuk membangun visi dan misi organisasi, menetapkan tujuan strategis dan keuangan perusahaan, serta merancang strategi untuk mencapai tujuan tersebut dalam rangka menyediakan customer value terbaik. Aktivitas yang termasuk dalam proses bisnis tersebut antara lain proses analisa, perencanaan, dan juga proses penentuan keputusan dilanjut dengan proses manajemen dari keseluruhan proses tersebut [11].

Strategi pemasaran dapat ditentukan dengan cara menentukan target konsumen terlebih dahulu, lalu memenuhi kebutuhan dari konsumen tersebut dengan sebaik-baiknya. Setelah itu tidak lupa juga menentukan cara dari perusahaan dalam menyampaikan value mereka pada konsumen. Beberapa proses tersebut secara singkat dapat dijabarkan dengan penentuan segmentasi pasar, sasaran pasar, posisi pasar, dan diferensiasi perusahaan [10].

\section{Strategi Pemasaran Model Scorpio}

Strategi pemasaran adalah proses dimana organisasi menyelaraskan dirinya dengan pasar yang ingin dilayani. Teknik Scorpio adalah proses berkelanjutan dari setiap perusahaan dan setiap perusahaan memiliki kerangka waktu sendiri untuk meninjau teknik ini, mungkin satu tahun atau satu bulan, atau mungkin dalam satu minggu atau lainnya. Adapun komponen dari Model SCORIO antara lain [12]:

1. Segmentation and Targeting. Ini adalah salah satu bidang yang sangat penting dimana organisasi telah melewatkan sepenuhnya di masa lalu karena pertempuran internal antara spesialis strategi perusahaan dan pemasar organisasi.

2. Customer. Strategi perusahaan organisasi berfokus pada pelanggan daripada berfokus pada produk atau produksi, tetapi terkadang kesulitan untuk mengidentifikasi "siapa pelanggannya", pembelajaran dari Model Scorpio menghasilkan organisasi mengantisipasi kebutuhan pelangan berkaitan dengan pengembangan produk dan layanan.

3. Organization Processes and Culture. Milik Manajemen Sumber Daya Manusia tetapi organisasi mengakui bahwa "tidak akan pernah terjadi kecuali orang-orang dalam organisasi ingin melakukannya" setelah semua orang dalam organisasi adalah "minyak di mesin mobil", untuk menggunakan agak sederhana tetapi metafora yang akurat.

4. Retention. Organisasi setuju dengan pekerjaan tentang loyalitas pelanggan dan efek selanjutnya, dimana ia menyatakan. Kita semua tahu bahwa mempertahankan pelanggan yang sudah ada jauh

\section{(i) (2)}


lebih menguntungkan daripada menghabiskan semua biaya untuk mendapatkan pelanggan baru.

5. Positioning and Branding. Organisasi menemukan ide bahwa, dengan memadukan positioning dan branding bersama-sama mulai mengidentifikasi rute dan proses yang memungkinkan organisasi untuk mencari posisi unik di pasar. Mengadopsi pendekatan ini telah menciptakan merek yang memiliki pasar, pelanggan, dan nilai finansial yang nyata.

6. Industry or Market. Pertanyaan ini mengambil seluruh area bisnis apa yang digeluti organisasi (industri) dan kontras dengan bisnis apa yang seharusnya digeluti organisasi (pasar).

7. Offering. Itu menyatukan pengetahuan yang dimiliki organisasi tentang kebutuhan pelanggan saat ini dan masa depan, pasar tempat kita berada, persaingan yang dihadapi, merek, diferensiasi, dan harga dengan cara yang kohesif yang telah terbukti, terkadang lebih berhasil daripada bauran pemasaran..

\section{METODE PENELITIAN}

Jenis Penelitian menggunakan metode Pemodelan SCORPIO dengan menggunakan beberapa literatur seperti buku, artikel, ataupun homepage sebagai sumber data sekunder tentunya yang berkaitan dengan implementasi model SCORPIO terhadap UMKM di masa pendemi COVID-19[13]. Model SCORPIO dimaksud dapat dilihat pada Gambar 1 berikut:

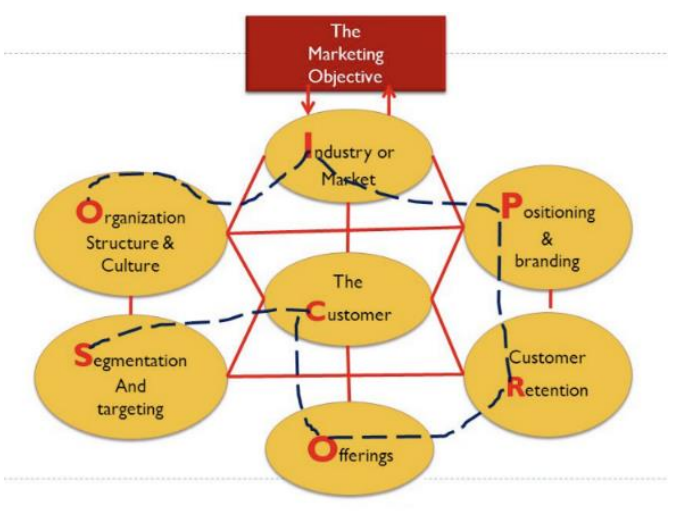

Gambar 1. Model SCORPIO[12]

Tujuan dari penelitian ini antara lain memberikan penjelasan serta memberikan gambaran yang dapat menyelesaikan rumusan masalah, antara lain mengenai tahapan Implementasi model SCORPIO pada strategi pemasaran pelaku usaha kecil pada masa pendemi COVID-19.

\section{HASIL DAN PEMBAHASAN}

Melalui situs resmi dari Kementerian Koperasi dan UMKM, pemerintah menyatakan bahwa pandemi COVID-19 ini akan sangat berpotensi berdampak langsung pada perekonomian dan juga keberlangsungan UMKM. Salah satunya ialah dengan adanya aturan pemerintah untuk tetap berada di rumah yang mana akan sangat berpengaruh besar pada roda perekonomian UMKM. Pandemi Covid-19 telah membuat mayoritas sektor ekonomi terutama UMKM menjadi stagnan. Eksesnya mayoritas pelaku UMKM tidak bisa berkembang dan banyak yang berakhir pada kebangkrutan. Hal inilah yang membuat, pelaku usaha UMKM mengubah strategi penjualan melalui skema digitalisasi. Skema digitalisasi yakni dengan memanfaatkan market place (perantara) dan menggunakan media sosial sebagai teknik pemasaran [13].

Beberapa studi terdahulu mengulas bahwa pelaku UMKM beralih pada pemanfaatan teknologi digital termasuk media sosial untuk pengembangan UMKM di Indonesia[14][15][16][17][18], sedangkan penelitian ini lebih pada upaya mengimplementasikan model SCORPIO pada masa pandemi Covid-19. Dengan ini UMKM Di masa pendemi COVID-19 ini bisa mengimplementasikan Strategi Pemasaran model SCORPIO. Strategi pemasaran yang dapat membantu memberikan pengarahan pada perusahaan komersial. Implemesatasi model SCORPIO pada strategi pemasaran pelaku usaha kecil pada masa COVID-19 yaitu sebagai berikut :

\section{Segmentation dan Targeting}

Dalam segmentasi pasar, UMKM harus mengidentifikasi dan juga mengelompokkan target pasar menjadi beberapa kelompok terpisah. Tiap kelompok konsumen dapat dipisahkan menurut kebutuhan produk yang diinginkan. Pada saat pandemi COVID-19 ini UMKM dapat menerapkan pengelompokkan target pasar atau konsumen tersebut sesuai dengan produk yang ditawarkan.

Dalam targeting pasar pelaku usaha kecil di masa pendemi COVID-19 ini melakukan kegiatan memilih dan menilai satu segmen pasar yang akan dimasuki di masa pandemi ini seperti segmen pasar dalam segi harga yaitu harga yang murah karena di masa pandemic ini ekonomi dalam kondisi rendah. 


\section{Customer}

Pada masa pendemi COVID-19 ini UMKM atau pelaku usaha kecil di sektor customer bisa melakukan customer reward [19]. Tujuannya adalah untuk mempertahankan kesetiaan pelanggan atau konsumen, sebagai daya tarik untuk mendapatkan konsumen, meningkatkan omset usaha, sebagai media promosi dan sebagai wujud rasa terima kasih. Terdapat banyak jenis benda atau barang yang bisa digunakan sebagai hadiah atau reward kepada konsumen.

\section{Organization, Procesess and Culture}

Dalam lingkungan internal perusahaan seperti struktur organisasi, proses produksi dan budaya di UMKM pada masa pandemi COVID-19 harus mengikuti prokol kesehatan. Contoh dalam proses produksi pegawai harus memakai masker dan menjaga kebersihan. Dengan ini menjadikan hal tersebut sebagai budaya dan kebiasaan di lungkungan internal perusahaan.

\section{Retention}

Dalam strategi pemasaran retention di UMKM pada masa pendemi COVID-19 pelaku usaha kecil disarankan untuk dapat menunjukan kepedulian terhadap konsumen setia yang sedang mengalami kesulitan pada saat COVID-19 ini. Contoh dalam menunujukan kepedulian terhadap konsumen yang setia atau loyalitas pelanggan yaitu memberikan promo dan skema free produk untuk kurir yang melakukan delivery service.

\section{Positioning and Branding}

Positioning and branding adalah komponen model SCORPIO dalam strategi pemasaran. Pada masa COVID-19 pelaku usaha kecil atau UMKM dapat mengurutkan atau mengatur posisi produk yang dijual berdasarkan harga atau berdasarkan target pasar dari produk tersebut. Dengan ini UMKM bisa menetukan posisi pasar dalam harga murah dan menurut kelas pengguna. Brand dalam produk UMKM di masa pandemi ini harus mempunyai nama, desain, atau simbol sebagai identitas dan untuk membedakan dengan produk lain.

\section{Industry or Market}

Pada masa pandemi COVID-19 pelaku usaha kecil atau UMKM dalam memasuki pasar yaitu ecommerce dan pemasaran digital. E-commerce merupakan suatu proses membeli dan menjual produkproduk secara elektronik oleh konsumen dan dari perusahaan ke perusahaan dengan komputer sebagai perantara transaksi bisnis [20]. Pemasaran digital adalah sebuah penggunaan teknologi terutama dalam bentuk teknologi informasi untuk melakukan segala proses bisnis termasuk didalamnya kegiatan jual beli produk, jasa dan informasi, meningkatkan permintaan melayani pelanggan dengan sentuhan digital.

7. Offering

Pada masa pandemi COVID-19 strategi pemasaran pelaku usaha kecil atau UMKM dalam offering yaitu perusahaan harus mengetahui kebutuhan konsumen di masa pandemi COVID-19. Pasar online sebagai pasar di masa pandemic COVID-19 meningkat dan menjadikan persaingan yang ketat, dengan ini UMKM harus melakukan harga yang sesuai dengan kebutuhan konsumen di kondisi COVID-19.

\section{KESIMPULAN DAN SARAN}

Pandemi COVID-19 yang terjadi di Indonesia memang berdampak terhadap perekonomian Indonesia terutama terhadap UMKM. Dengan implementasi model SCORPIO ini terhadap strategi pemasaran pelaku usaha kecil atau UMKM bisa membantu mempertahankan usaha di masa pandemi ini dengan mengimplementasikan ketujuh komponen pada model, antara lain Segmentasi dan Targeting Pasar, Customer Reward, Struktur organisasi, Proses produksi dan Budaya di UMKM berbasis Protokol Kesehatan Covid-19, Free Product for Delivery Service (Retention), Product Positioning \& Branding, ECommerce \& Digital Marketing dan Pricing pada Online Market yang kompetitif.

Adapun saran yang bisa dirokemendasikan untuk implementasi model SCORPIO terhadap strategi pemasaran pelaku usaha mikro dan kecil di masa pandemi COVID-19 ini yaitu menerapkan strategi pemasaran berdasarkan model SCORPIO dengan situasi kondisi yang sedang dihadapi perusahaan. Pelaku UMKM harus membiasakan diri untuk menyusun catatan penjualan, agar mengetahui apakah kurva penjualan mengalami kenaikan atau penurunan. Pelaku usaha juga dapat sangat terbantu dengan adanya catatan pejualan, dikarenakan dapat merespon dengan cepat apa yang harus dilakukan oleh UMKM sesuai dengan kondisi penjualan. Pada masa pandemi Covid19 yang mengakibatkan banyak pengusaha UMKM terancam gulung tikar, ada baiknya pelaku UMKM lebih berkoordinasi atau bekerja sama dengan pemerintah daerah atau dinas koperasi dan UMKM setempat untuk mencari solusi agar UMKM tetap bertahan, berkembang dan beradaptasi dengan baik 
dalam berbagai kondisi pasar. Perumusan strategi pemasaran perlu dilakukan secara berkala untuk mendapatkan gambaran pasar yang dinamis. Hal ini dilakukan karena kondisi pasar yang berubah setiap saat.

\section{REFERENSI}

[1] Wordometer, 2020. Covid-19 Coronavirus Pandemic, https://www.worldometers.info/ coronavirus/

[2] Sugiri, D. 2020. Menyelamatkan Usaha Mikro, Kecil dan Menengah dari Dampak Pandemi Covid-19. Fokus Bisnis: Media Pengkajian Manajemen Dan Akuntansi, Vol. 19, No. 1, pp. 76-86, https://doi.org/10.32639/fokusbisnis. v19i1.575

[3] Sarfiah, S., Atmaja, H., \& Verawati, D. 2019. UMKM Sebagai Pilar Membangun Ekonomi Bangsa. Jurnal REP (Riset Ekonomi Pembangunan), Vol. 4, No. 2, pp. 1-189, https://doi.org/10.31002/rep.v4i2.1952

[4] Sutrisno, N., \& Haryani, A. D. 2017. Influence of Brand and Product Quality on Customer'S Buying Decision in South Cikarang Bekasi Regency. Jurnal Lentera Bisnis, Vol. 6, No. 1, pp. 85, https://doi.org/10.34127/jrlab.v6i1.169

[5] Wibowo, D. H., Arifin, Z., \& Sunarti. 2015. Analisis Strategi Pemasaran Untuk Meningkatkan Daya Saing UMKM. Jurnal Administrasi Bisnis, Vol. 29, No. 1, pp. 59-66

[6] Jayanti Mandasari, D., Widodo, J., \& Djaja, S. 2019. Strategi Pemasaran Usaha Mikro, Kecil Dan Menengah (Umkm) Batik Magenda Tamanan Kabupaten Bondowoso. JURNAL PENDIDIKAN EKONOMI: Jurnal Ilmiah Ilmu Pendidikan, Ilmu Ekonomi Dan Ilmu Sosial, Vol. 13, No. 1, pp. 123, https://doi.org/10.19184/ jpe.v13i1.10432

[7] UU No. 20 Tahun 2008, Usaha Mikro,Kecil \& Menengah

[8] LPPI. 2015. Profil Bisnis Usaha Mikro, Kecil dan Menengah (UMKM). Lembaga Pengembangan Perbankan Indonesia (LPPI) dan Bank Indonesia (BI)

[9] Manullang, M dan Hutabarat, E. 2016. Manajemen Pemasaran Dalam Kompetisi Global. Yogyakarta : Indomedia Pustaka

[10] Kotler, P dan Amstrong, G. 2016. Principles of Marketing, 15th Pearson Education Limited

[11] David, Fred R. 2006. Manajemen Strategis : Konsep. Edisi Sepuluh. Jakarta : Salemba Empat

[12] Paul Fifield. 2017. Marketing Strategy : The Difference Between Marketing and Markets
(Third Ed). Amsterdam; Boston: Elsevier/Butterworth-Heinemann

[13] Arianto, Bambang. 2020. Pengembangan UMKM Digital Di Masa Pandemi Covid-19. ATRABIS: Jurnal Administrasi Bisnis, Vol. 6, No.2, pp. 233247

[14] Anggia, M. N., \& Shihab, M. R. 2018. Strategi Media Sosial Untuk Pengembangan Umkm.Jurnal Terapan Teknologi Informasi, Vol. 2, No. 2, 159-170.

[15] Idah, Y. M., \& Pinilih, M. 2019. Strategi Pengembangan Digitalisasi UMKM. Prosiding, Jurnal LPPM Unsoed. Vol. 9, No. 1

[16] Putra, I. N. T. A., Kartini, K. S., \& Dewi, L. G. K. 2019. Sentuhan Digital Bisnis (Teknologi Informasi) Pada UMKM Studi Kasus: Pemasaran Produk Adi Upakara. International Journal of Natural Science and Engineering. Vol. 3, No. 2. pp. 79-84

[17] Bakhri, S., \& Futiah, V. 2020. Pendampingan dan Pengembangan Manajemen Pemasaran Produk UMKM Melalui Teknologi Digital Di Masa Pandemi Covid-19. Jurnal Loyalitas Sosial : Journal of Community Service in Humanities and Social Sciences. Vol. 2, No. 2, pp. 59-70

[18] Sumarni, T., Melinda, L. D. 2020. Media Sosial dan E-Commerce sebagai Solusi Tantangan Pemasaran Pada Masa Pandemi Covid-19 (Studi Kasus: UMKM Warung Salapan). ATRABIS : Jurnal Administrasi Bisnis. Vol. 6, No. 2, pp. 163171

[19] Siagian, A. O., \& Cahyono, Y. 2021. Strategi Pemulihan Pemasaran UMKM di Masa Pandemi Covid-19 Pada Sektor Ekonomi Kreatif. Jurnal Teknologi Dan Sistem Informasi Bisnis, Vol. 3, No. 1, pp. 206-217, https://doi.org/10.47233/ jiteksis.v3i1.212

[20] Anugrah, R. J. 2020. Efektifitas Penerapan Strategi Online Marketing Oleh UMKM Dalam Masa Pembatasan Sosial Berskala Besar (PSBB) Corona Viruses Disease 2019 (Covid-19). Jurnal Manajemen Dan Inovasi (MANOVA), Vol. 3, No. 2, pp. 55-65, https://doi.org/10.15642/ manova.v3i2.302

\section{(i) (2)}

